\title{
Thickness Optimization of Pressure Vessel for Minimum Weight using Finite Element Method (FEM)
}

\author{
Heru Susiawan Widiharso ${ }^{\# 1}$, Mohammad Tauviqirrahman ${ }^{\# 2}$, Muchammad ${ }^{* 3}$, J. Jamari ${ }^{\#}$ \\ ${ }^{\#}$ Laboratory for Engineering Design and Tribology, \\ Department of Mechanical Engineering, Diponegoro University \\ Jl. Prof. Soedharto, Tembalang, Semarang 50275, Indonesia, Phone: +62-24-7460059 \\ ${ }^{1}$ heru.s.widiharso@gmail.com \\ ${ }^{2}$ mohammad.tauviqirrahman@ft.undip.ac.id \\ * Laboratory for Surface Technology and Tribology, Faculty of Engineering Technology, \\ University of Twente, Drienerloolaan 5, Postbus 217, 7500AE, Enschede, The Netherlands \\ 3 m_mad5373@yahoo.com
}

\begin{abstract}
Design parameter optimization based on finite element method (FEM) simulations is presented here. The aim of this paper is to perform the detailed design \& analysis of pressure vessel for optimum thickness using finite element method based commercial software ANSYS. Several geometrical models of pressure vessel are proposed and compared by optimization method. The diameter and the length of the pressure vessel are varied. It is shown that a direct optimization gives the minimum weight of pressure vessel with optimum wall thickness. The optimized pressure vessel is able to carry the internal load with same safety factor but lower weight compared to the existing model.
\end{abstract}

Keywords- Finite element method (FEM), Pressure vessel, Optimization, Von Mises stress

\section{INTRODUCTION}

The pressure vessels are used to store fluids under large internal pressure. A great care should be applied when the analysis as well as the design of pressure vessel is performed. This is because the fluid may undergo a change of state inside the pressure vessel. A rupture of a pressure vessel and thus an explosion leads to loss of lifetime and the reduced reliability of the pressure vessel.

Regarding with the appropriate structural design of the pressure vessel, the optimization approach has paid much attention by many researchers both in practice and research. Zhu et al. [1] carried out the optimization for the shapes for axisymmetric pressure vessels. Abdi et al. [2] investigated the effective proportion of the pressure vessel dimensions under stability and strength constraints using imperialist competitive algorithm. Carbonari et al. [3] discussed the shape optimization of axisymmetric pressure vessels considering an integrated approach in which the entire pressure vessel model is used in conjunction with a multi-objective function that aims to minimize the von Mises mechanical stress from nozzle to head. Nasseri et al. [4] proposed an optimized solution of pressure vessel design using geometric programming. It was found that compared to other optimization problems, geometric programming gives the better solution of design. Interesting study was reported by Proczka et al. [5]. They proposed the guidelines for the efficient design and sizing of pressure vessels, including guidelines for pressures that should be used in the system to minimize the cost of the pressure vessel. They also suggested that pressure vessels with a length to diameter ratio of roughly three are the most economical, and that a system should be designed for a pressure of roughly three times the minimum pressure of the expansion device. Hassan et al. [6] proposed the Omicron ACO (OA), a novel population-based ACO alternative originally designed as an analytical tool for designing and optimisation of pressure vessel. They made the comparison of the effectiveness of the three methods on a particular optimization problem, namely the tuning of the parameters for a PID controller. It was found that the ACO are better as its search is for global optimum as against the local optimum in traditional search method. Talebitooti et al. [7] used the multi-objective genetic algorithm, sum of weighted cost function and Pareto solution for enhancing roll stability of fuel tank shape. In addition, a finite element method (FEM) based commercial software ANSYS is also of particular interest in area of the optimization as well as the analysis, for example, [8], [9], [10]. Patel et al. [8] using FEM performed the design and optimization of LNG-CNG cylinder for optimum weight.

In the present work, design analysis and optimization of pressure vessel with capacity of 2598 litre has been studied. This paper presents a method that directly minimizes the weight of the vessel by optimally determining the wall thickness. The optimization procedure is carried out using finite element method based commercial software ANSYS. The results presented here do contribute to a better understanding of the optimization method. 


\section{METHODOLOGY}

To achieve the main purpose of the research, the following methodology has been used. Figure 1 depicts the flow chart for simulation studied here. A pressure withstands a pressure of 200 psi. Modelling of pressure vessels is carried out by SOLIDWORKS (Figure 2). In real application, the existing dimension of the pressure vessel is fitted on the room and the specification for the pressure vessel is as follows:

- Diameter of the vessel $\quad=1350 \mathrm{~mm}$

- Capacity of the vessel $=2598$ litre

- Operating pressure of the vessel $=200 \mathrm{Psi}$

- Total length of the vessel $=2065 \mathrm{~mm}$

- Head Thickness = $12 \mathrm{~mm}$ (Ellipsoidal 2:1)

- Shell Thickness $\quad=10 \mathrm{~mm}$

- Mass $\quad=938.55 \mathrm{~kg}$

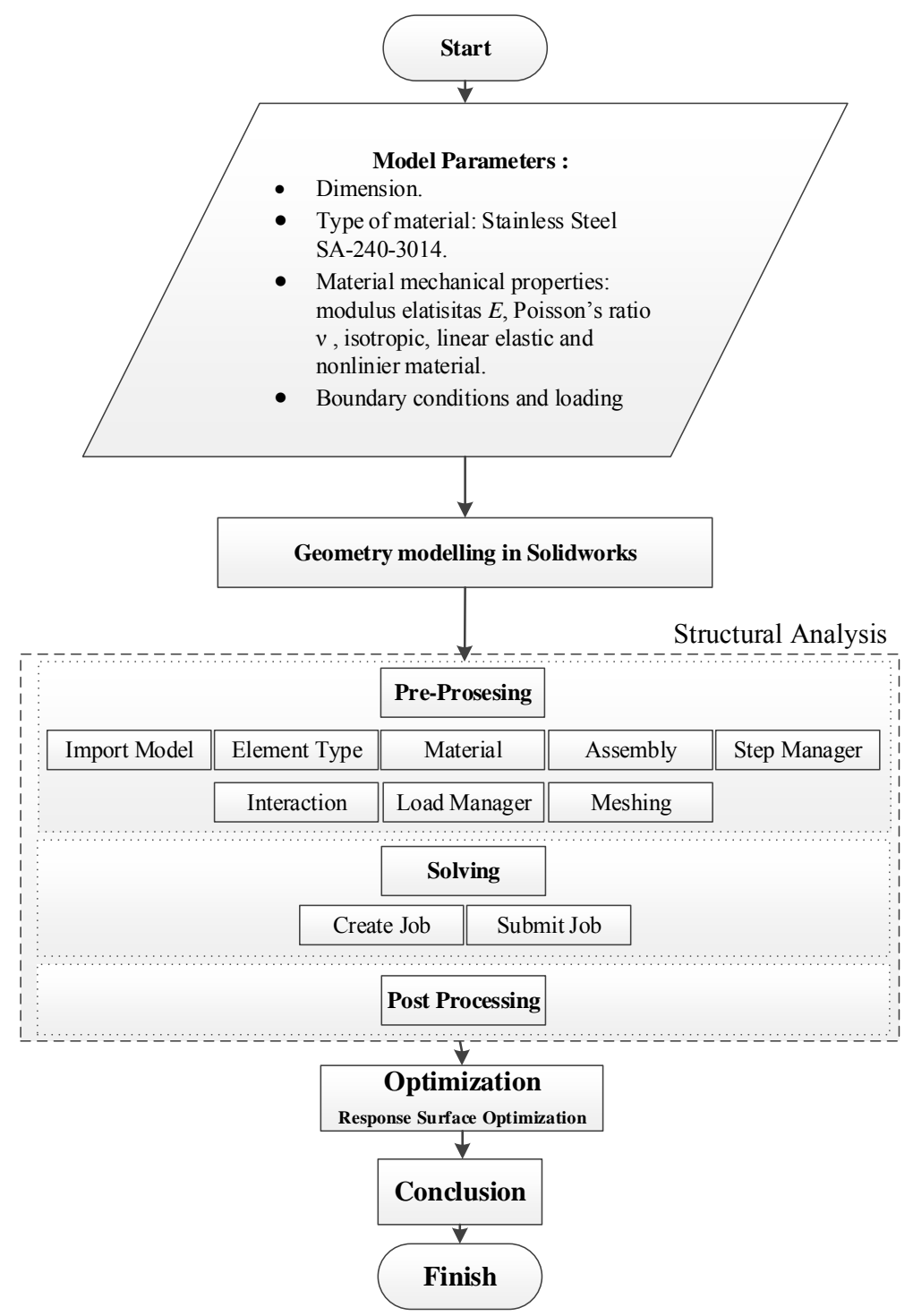

Figure 1. Flow chart used in this work 


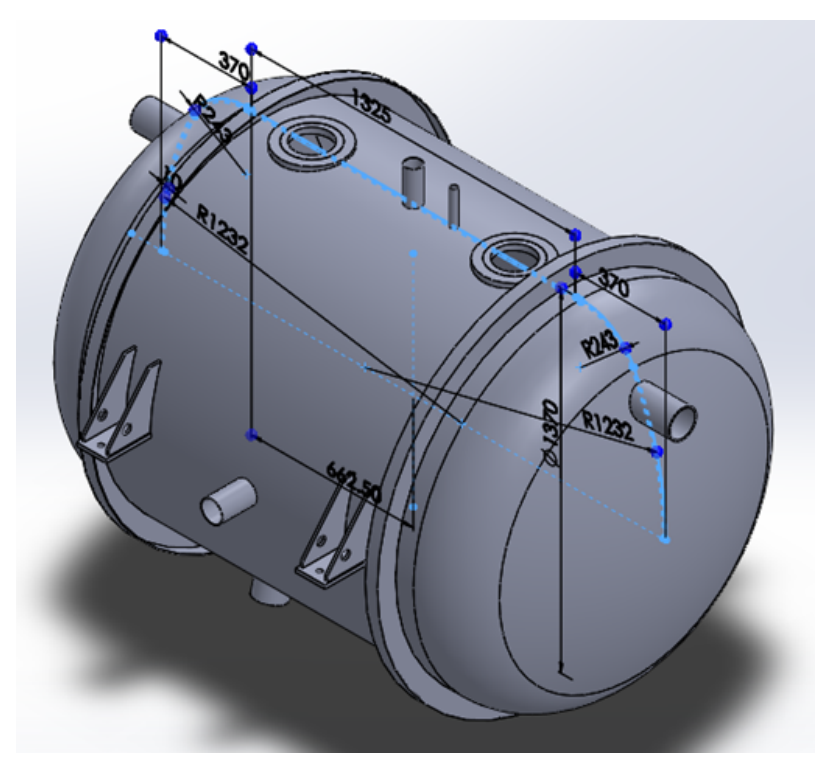

Figure 2. Pressure vessel model

The material used for all following computations is SA-240-304. In detail, the mechanical properties of SA240-304 are described in Table I.

TABLE I. Mechanical Properties of Material Used in this Simulation

\begin{tabular}{|c|c|c|}
\hline Description & Unit & Value \\
\hline Density & $\mathrm{kg} / \mathrm{m}^{3}$ & 8000 \\
\hline Yield Strength & $\mathrm{MPa}$ & 250 \\
\hline Ultimate Tensile Strength & $\mathrm{MPa}$ & 505 \\
\hline Modulus of Elasticity & $\mathrm{GPa}$ & 200 \\
\hline Poison Ratio & - & 0.29 \\
\hline
\end{tabular}

Then, the geometry model is imported to ANSYS and the analysis as well as the optimization is carried out in ANSYS. Meshing is performed using auto-meshing, one of the features provided in ANSYS (Figure 3). Finally, the boundary conditions are applied to ensure the right solution (Figure 4).

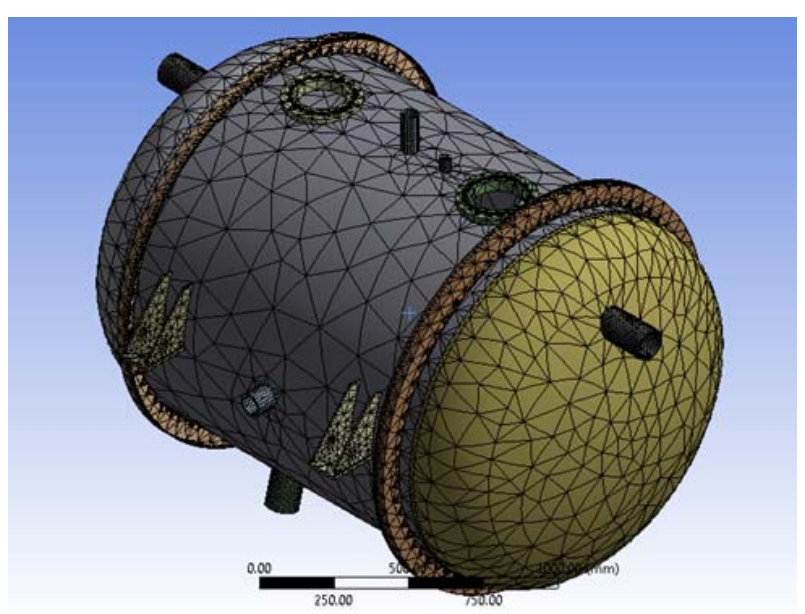

Figure 3. Mesh of model 


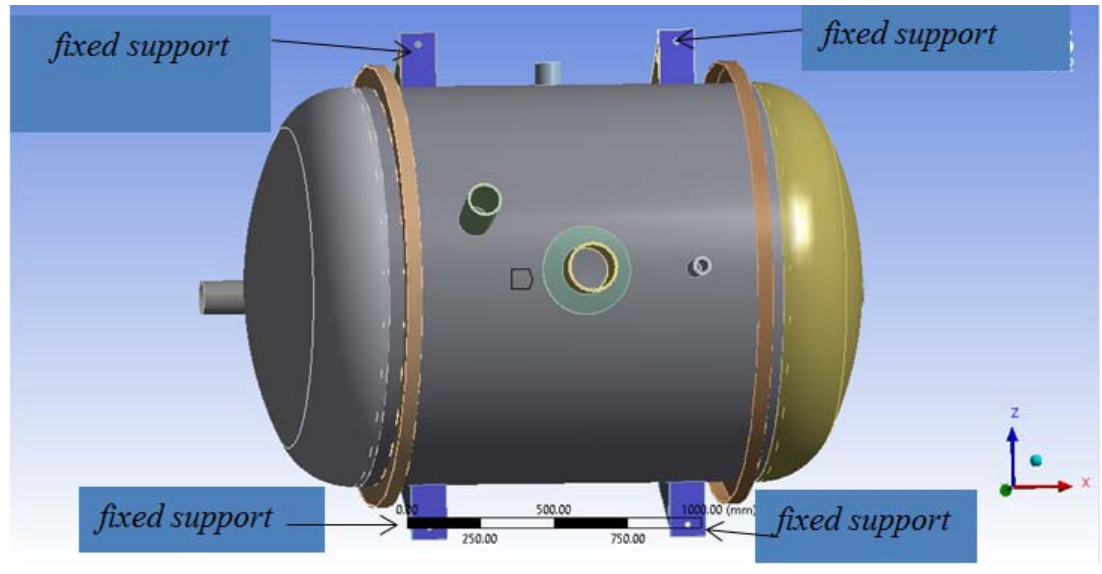

Figure 4. Boundary condition applied for simulation

The problem taken to exemplify this is that of minimizing the mass (and thus the weight) of the pressure vessel. The goal here is to determine the wall thickness of the pressure vessel which offers minimum weight. In the project setup, design optimization requires identification of input and output parameters. In the present study, the input parameter, i.e. the wall thickness is the geometric parameter that is to be optimized. Output parameters which are typically expression values evaluated post simulation are the von Misses stress and the mass of the vessel. Design optimization studied here is summarized in Table II.

TABLE II. Optimization Variables

\begin{tabular}{|l|l|}
\hline \multicolumn{1}{|c|}{ Variable } & \multicolumn{1}{c|}{ Description } \\
\hline Design Variables, DVs & Wall thickness \\
\hline State Variables, SVs & Local von Mises stress $<$ Yield stress \\
\hline Objective Function & Minimize mass (m Min) \\
\hline
\end{tabular}

III.RESULTS AND DISCUSSION

\section{A. Response Surface Optimization}

Referring to the dimension of the machine structure, the rest space of the machine room for which the pressure vessel will be optimized, has the dimension of $136 \times 40 \times 640 \mathrm{~mm}^{3}$ (length $\mathrm{x}$ wide $\mathrm{x}$ height). This space is subjected to a baseline to vary the diameter and the length of the pressure vessel. In the following simulations, there are two parameters, which are the base of the simulation:

1. Diameter of the pressure vessel

2. Length of the pressure vessel

Table III shows the simulation cases represent various designs of the pressure vessel. These models have been proposed based on the variables of the diameter and the length of the pressure vessel.

TABLE III. Simulated and Optimized Cases for Simulation

\begin{tabular}{|c|c|c|c|c|c|}
\hline Model & Diameter (mm) & $\begin{array}{c}\text { Length of shell } \\
(\mathbf{m m})\end{array}$ & $\begin{array}{c}\text { Volume of } \\
\text { cylinder }\left(\mathbf{m m}^{\mathbf{3}} \mathbf{)}\right.\end{array}$ & $\begin{array}{c}\text { Volume of } \\
\text { head }\left(\mathbf{m m}^{\mathbf{3}} \mathbf{)}\right.\end{array}$ & $\begin{array}{c}\text { Total volume } \\
\mathbf{( m m}^{\mathbf{3}} \mathbf{)}\end{array}$ \\
\hline 1 & 1360.00 & 1338.40 & 1943.27 & 654.34 & 2597.61 \\
\hline 2 & 1380.00 & 1286.92 & 1923.89 & 673.73 & 2597.61 \\
\hline 3 & 1370.00 & 1312.37 & 1933.60 & 664.00 & 2597.60 \\
\hline 4 & 1390.00 & 1262.00 & 1914.07 & 683.53 & 2597.60 \\
\hline 5 & 1337.53 & 1399.00 & 1964.69 & 632.90 & 2597.59 \\
\hline 6 & 1325.41 & 1433.00 & 1976.13 & 621.48 & 2597.61 \\
\hline 7 & 1313.61 & 1467.00 & 1987.16 & 610.46 & 2597.62 \\
\hline 8 & 1302.11 & 1501.00 & 1997.77 & 599.82 & 2597.59 \\
\hline
\end{tabular}


In order to minimise weight of vessel, the wall thickness is of particular interest as the design variable. However, the predicted appropriate thickness refers to the available room space as stated in the previous section. The optimisation analysis is performed in ANSYS. The ANSYS program offers two optimisation methods to accommodate a wide range of optimisation problems. In optimization scheme, ANSYS design exploration offers response surface generation and response surface optimization. In the present study, response surface optimization is used because it is particularly suitable for cases with larger degree of freedom sets. Prior to the optimization step, the analysis will be performed based on the initial design as shown in Fig. 1. For the optimization step, the analysis of the initial design is performed at first, and then the results are evaluated against specified design criteria, and the design is modified as necessary. This process is repeated until all specified criteria are met. All steps are performed in response surface optimization menu. The optimisation variables refer to the design variables, state variables, and objective function. In ANSYS optimisation, these variables are called parameters. Which parameters in the model are design variables (DVs), which are state variables (SVs), and which is the objective function must be identified. Figure 5 shows the schematic of connection of menu for response surface optimization in ANSYS.

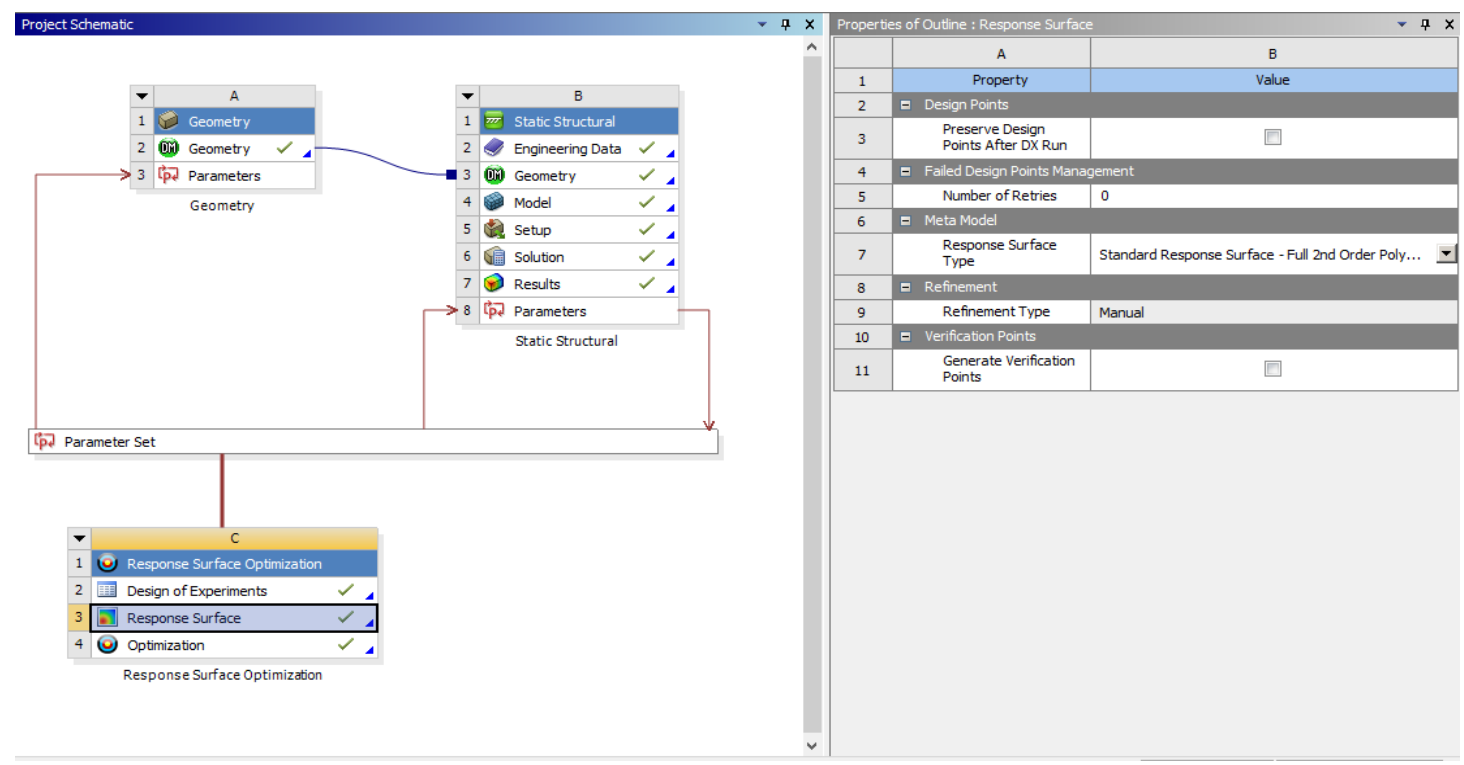

Figure 5. Schematic of response surface optimization

\section{B. Optimization Results}

Table IV reflects the initial design and the optimization results based on the methodology as described in the previous section. The maximum von Mises stress and the safety factor are of particular interest. They represent the von Mises failure criteria which can be used to predict the possibility of the failure of the pressure vessel. Based on Table III, it can be seen that the model 1, 2, 3 and 4 gives the minimum wall thickness. However, among these models, the model 4 gives the minimum mass, which means provides the minimum weight of the pressure vessel. The other finding is that only two models which give the predicted safety factor which is higher than 1.0. It indicates that the choice of the appropriate model, i.e. the model 4, as the best design of the pressure vessel is the right decision.

From the manufacturing point of view, the model 4 may be difficult to manufacture due to the availability of the raw material (dimension and cutting process). Therefore, in the present work, the optimization result has been redesign with the aim to the easy of the manufacturing of the geometry of the pressure vessel. The approach considered here is by introducing the area of the reinforcement to the nozzle from the area of 70,650 $\mathrm{mm}^{2}$ to $125,600 \mathrm{~mm}^{2}$. Based on the simulation result, it is found that the maximum von Misses is around 196.96 $\mathrm{MPa}$ and the safety factor equivalent von Misses stress due to the maximal loading is 1.06. Figure 6 and 7 present the distribution of von Misses stress and the safety factor equivalent von Misses stress of the final optimized pressure vessel, respectively. From these figures, it can be observed that the critical stress occurs at the area in which the large change of curved surface (such as support and nozzle). On the other words, the maximum stress does not occur on the wall of vessel. From the engineering point of view, it can be considered as a safe design, because the initial failure will not occur on the vessel. The result also shows that the mass of the pressure vessel is $861.07 \mathrm{~kg}$. Based In general, the pressure vessel is still able to carry the static loading and thus it is in a safety condition. 
TABLE IV. Initial Design and Optimization Results

\begin{tabular}{|c|c|c|c|c|c|}
\hline Model & $\begin{array}{c}\text { Mass } \\
\mathbf{( k g )}\end{array}$ & $\begin{array}{c}\text { Max Von Mises } \\
\text { stress (MPa) }\end{array}$ & $\begin{array}{c}\text { Thickness of } \\
\text { Head (mm) }\end{array}$ & $\begin{array}{c}\text { Thickness of } \\
\text { Shell (mm) }\end{array}$ & $\begin{array}{c}\text { Safety } \\
\text { Factor }\end{array}$ \\
\hline Initial & 938.55 & 201.31 & 12.00 & 10.00 & 1.03 \\
\hline 1 & 851.88 & 224.83 & 10.80 & 9.00 & 0.97 \\
\hline 2 & 850.70 & 210.16 & 10.80 & 9.00 & 0.91 \\
\hline 3 & 851.54 & 226.42 & 10.80 & 9.00 & 1.02 \\
\hline 4 & 848.00 & 199.96 & 10.80 & 9.00 & 1.02 \\
\hline 5 & 860.48 & 245.11 & 10.82 & 9.13 & 0.98 \\
\hline 6 & 884.20 & 248.32 & 10.83 & 9.64 & 0.84 \\
\hline 7 & 896.72 & 246.96 & 10.08 & 10.03 & 0.89 \\
\hline 8 & 856.18 & 233.10 & 10.80 & 9.00 & 0.87 \\
\hline
\end{tabular}

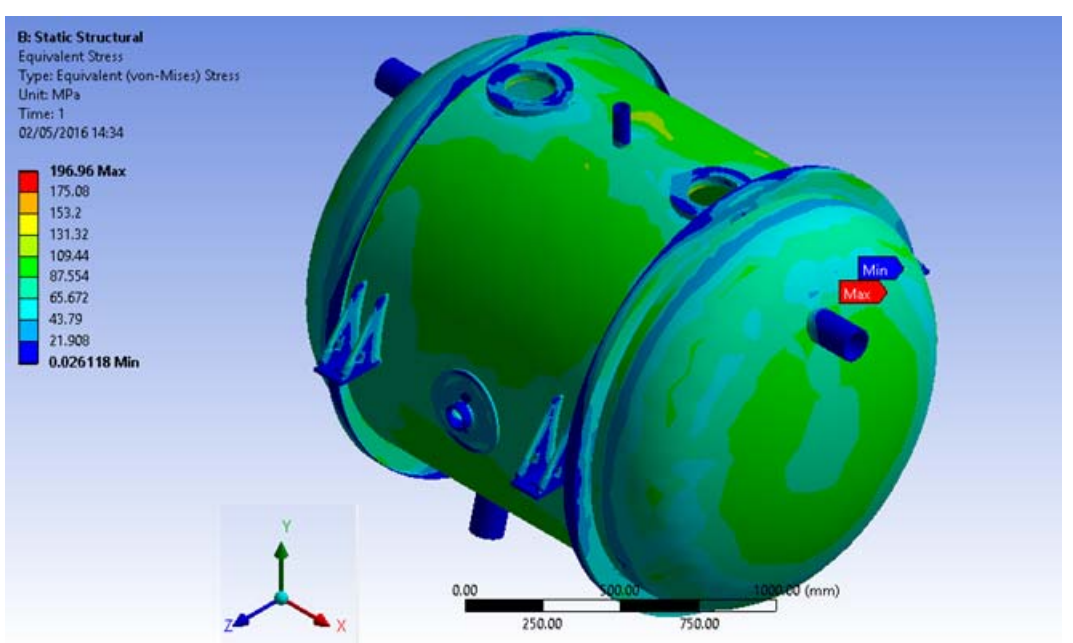

Figure 6. Von Mises stress contour of the optimized vessel

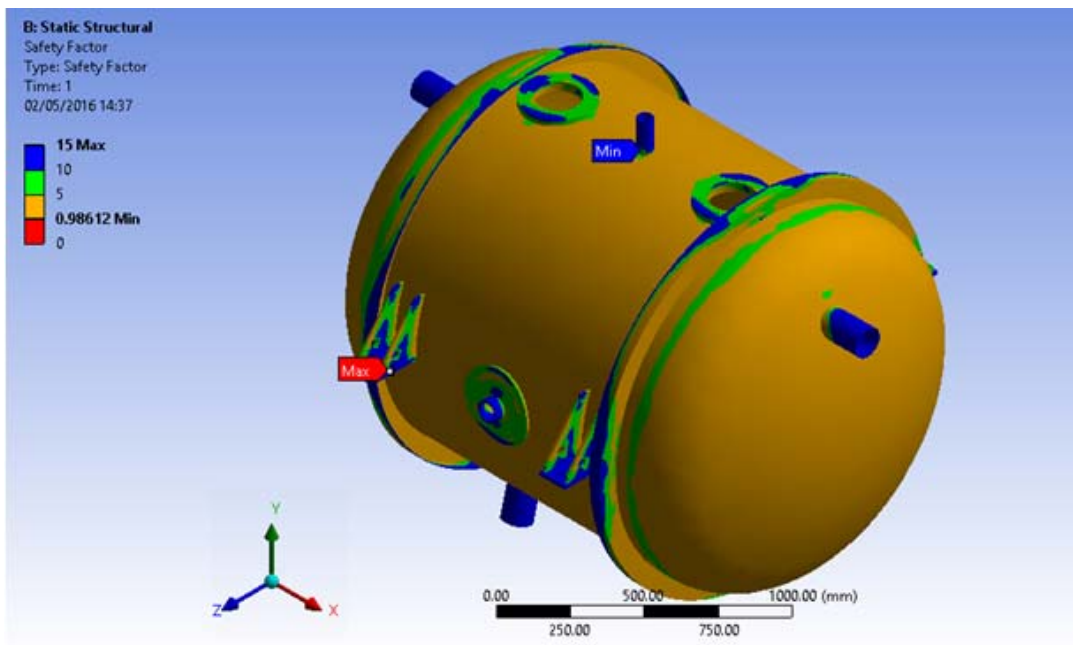

Figure 7. Safety factor contour of the optimized vessel 


\section{IV.CONCLUSION}

The paper presented a pressure vessel optimization for minimizing the weight and improving the safety factor. Several models of pressure vessel designs with the constant volume were proposed varying the wall thickness and the length of the vessel. A direct optimization analysis was conducted using the optimization tool developed in ANSYS. The conclusions can be summarized as follows:

1 The optimal design of pressure vessel is achieved when the diameter is $1390 \mathrm{~mm}$ and the length is 1262 $\mathrm{mm}$, the head thickness is $10.8 \mathrm{~mm}$, and the shell thickness is $9 \mathrm{~mm}$.

2 The optimization result gives the minimum mass of $848 \mathrm{~kg}$ or $10 \%$ lower compared to the initial design of the pressure vessel and the same safety factor.

\section{REFERENCES}

[1] L. Zhu and J. T. Boyle, "Optimal Shapes for Axisymmetric Pressure Vessels: A Brief," J. Press. Vessel Technol., vol. 122, no. November, pp. 443-449, 2000

[2] B. Abdi, H. Mozafari, A. Ayob, and R. Kohandel, "Optimum Size of a Ground-Based Cylindrical Liquid Storage Tank under Stability and Strength Constraints Using Imperialist Competitive Algorithm,” Appl. Mech. Mater., vol. 110-116, pp. 3415-3421, 2011.

[3] R. C. Carbonari, P. a. Muñoz-Rojas, E. Q. Andrade, G. H. Paulino, K. Nishimoto, and E. C. N. Silva, "Design of Pressure Vessels using Shape Optimization: An integrated approach,” Int. J. Press. Vessel. Pip., vol. 88, no. 5-7, pp. 198-212, 2011.

[4] S. H. Nasseri, Z. Alizadeh, and F. Taleshian, "Optimized Solution of Pressure Vessel Design Using Geometric Programming," J. Math. Comput. Sci., vol. 4, no. 3, pp. 344-349, 2012.

[5] J. J. Proczka, K. Muralidharan, D. Villela, J. H. Simmons, and G. Frantziskonis, "Guidelines for The Pressure and Efficient Sizing of Pressure Vessels for Compressed Air Energy Storage,” Energy Convers. Manag., vol. 65, pp. 597-605, 2013.

[6] S. Hassan, K. Kumar, C. D. Raj, and K. Sridhar, "Design and Optimization of Pressure Vessel Using Metaheuristic Approach," Appl. Mech. Mater., vol. 465, pp. 401-406, 2014.

[7] R. Talebitooti, M. H. Shojaeefard, and S. Yarmohammadisatri, "Shape Design Optimization of Cylindrical Tank Using b-Spline Curves," Comput. Fluids, vol. 109, no. October, pp. 100-112, 2015.

[8] P. M. Patel, P. J. Rana, M. E. C. A. D. C. A. M. Student, and M. Engineering, "Design \& Optimization of LNG-CNG Cylinder for Optimum Weight," Int. J. Sci. Res. Dev., vol. 1, no. 2, pp. 254-258, 2013.

[9] P. V. V Saidpatil and P. A. S. Thakare, "Design \& Weight Optimization of Pressure Vessel Due to Thickness Using Finite Element Analysis," Int. J. Emerg. Eng. Res. Technol., vol. 2, no. 3, pp. 1-8, 2014.

[10] K. S. Raju and S. S. Rao, "Design Optimization of a Composite Cylindrical Pressure Vessel Using FEA,” Int. J. Sci. Res. Publ., vol. 5, no. 12 , pp. 522-530, 2015. 